\title{
Poor performance of the pediatric airway exchange catheter in adults with cervical spine immobilization
}

\author{
[Performances insatisfaisantes d'un échangeur de sonde pédiatrique chez des \\ adultes présentant une immobilisation de la colonne cervicale]
}

Duk-Kyung Kim MD, Hae-Kyoung Kim MD, Kyoung-Min Lee MD, Hwa-Yong Shin MD, Jae-Sung Ryu MD

\begin{abstract}
Purpose: Use of a pediatric airway exchange catheter (PAEC) has been advocated as a potentially useful adjunct for difficult extubations. We evaluated the laryngeal passing ability of a tracheal tube over a PAEC and compared its success rate between adult patients in the sniffing position and adult patients with simulated cervical spine immobilization created using a manual in-line axial stabilization (MIAS) technique.
\end{abstract}

Methods: A total of 100 adult patients were randomized into two groups of equal size with respect to position during the simulated reintubation trial: the MIAS position (Group M) and the sniffing position (Group S). After induction of anesthesia, an II-F PAEC was placed in the trachea under direct laryngoscopic view, and a wire-reinforced tube (with its bevel facing to the left) was gently railroaded over the PAEC and into the trachea. If insertion was impeded, a second attempt was made after rotating the tube $90^{\circ}$ counterclockwise. If this also failed, one additional attempt was made using external laryngeal pressure before changing to conventional laryngoscopic intubation.

Results: After the second attempt, the cumulative success rates in Groups $M$ and $S$ were $41.3 \%$ and $72.3 \%$, respectively $(P=0.003)$. After three attempts, the overall success rate was significantly lower in Group M (52.2\%) than in Group S (76.6\%) $(P=0.018)$.

Conclusion: Owing to the high failure rate of PAEC-guided intubation in patients with simulated cervical spine immobilization, use of a PAEC is not recommended for maintaining continuous airway access after extubation in adult patients with cervical immobility or instability.

CAN J ANESTH 2008/55: $11 /$ pp 748-753
Objectif : L'utilisation d'un échangeur de sonde pédiatrique (PAEC) $a$ été recommandée en tant que complément potentiellement utile dans le cas d'extubations difficiles. Nous avons évalué la capacité de passage au niveau laryngé d'une sonde trachéale par rapport à une PAEC et comparé son taux de réussite entre des patients adultes en position de reniflement et des patients adultes présentant une immobilisation simulée de la colonne cervicale, créée à l'aide d'une technique de stabilisation manuelle axiale en ligne (MIAS).

Méthode : Au total, 100 patients adultes ont été randomisés en deux groupes de taille égale selon leur position pendant l'essai de réintubation simulée : la position MIAS (groupe $M$ ) et la position de reniflement (groupe S). Après l'induction de l'anesthésie, une PAEC II-F a été placé dans la trachée sous vision laryngoscopique directe, et une sonde à armature métallique (le biseau orienté vers la gauche) a été doucement acheminée au-dessus du PAEC et dans la trachée. Si l'insertion était entravée, une deuxième tentative était effectuée après avoir tourné la sonde de $90^{\circ}$ dans le sens inverse des aiguilles d'une montre. Si cette deuxième tentative échouait, une tentative supplémentaire était effectuée à l'aide de pression laryngée externe avant de passer à une intubation laryngoscopique traditionnelle.

Résultats : Après la deuxième tentative, les taux de réussite cumulatifs dans les groupes $M$ et $S$ étaient de $41,3 \%$ et $72,3 \%$, respectivement $(P=0,003)$. Après trois tentatives, le taux de réussite global était significativement plus bas dans le groupe $M(52,2 \%)$ que dans le groupe $S(76,6 \%)(P=0,018)$.

Conclusion : En raison du taux d'échec élevé d'une intubation guidée par le PAEC chez des patients présentant une immobilisation simulée de la colonne cervicale, l'utilisation du PAEC n'est pas recommandée si l'on doit maintenir un accès continu aux voies respiratoires après extubation chez les patients au rachis cervical immobilisé ou instable.

From the Department of Anesthesiology and Pain Medicine, Konkuk University School of Medicine, Seoul, South Korea.

Address correspondence to: Dr. Duk-Kyung Kim, MD, Assistant Professor, Department of Anesthesiology and Pain Medicine, Konkuk

University School of Medicine, 1 Hwayang-Dong, Gwanggin-Gu, Seoul, 143-701, South Korea. Phone: 82-2-2030-5442; Fax: 82-2-

2030-5422; E-mail: dikei@kuh.ac.kr

The authors received no financial support from any pharmaceutical or medical device companies.

Accepted for publication July 21, 2008.

Revision accepted August 25, 2008. 


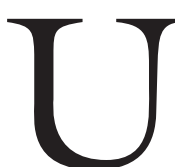

NPLANNED or premature extubation of patients with risk factors for difficult tracheal reintubation presents a serious challenge for both anesthesiologists and intensive care physicians. Cervical immobility and instability are well-known risk factors in difficult intubations. ${ }^{1,2}$ When acute respiratory distress develops in these patients after tracheal extubation, reintubation by conventional laryngoscopy may be difficult or impossible because of limited neck mobility. Moreover, failure to immobilize the neck during intubation in such patients can result in devastating neurological outcomes. ${ }^{3}$ Thus, simply for concern of the inability to reintubate these patients, they often remain tracheally intubated for longer periods than necessary. Consistent with this, almost half of intensive care unit (ICU) patients with unplanned extubations did not actually require tracheal reintubation. ${ }^{4}$ The delay in timely extubation increases the risk of complications, and, as a consequence, total hospital costs, because it necessitates respiratory therapy, more extensive monitoring, and prolonged ICU stays. ${ }^{5}$

The use of a pediatric airway exchange catheter (PAEC) has been advocated as a potentially useful method of performing a safe "trial" extubation in patients at risk for a difficult reintubation. ${ }^{6-8}$ In these patients, the PAEC is inserted into the tracheal tube before extubation, and the tube is then removed leaving the PAEC in the trachea until it becomes clinically apparent that the need for reintubation is unlikely. This indwelling catheter can be used as a conduit for jet ventilation, apneic oxygenation, or reintubation, if necessary, and, therefore, it allows a "reversible" extubation. However, no data are available regarding the success rate of passing a tracheal tube over a PAEC and into the trachea of patients with cervical immobility or instability.

This randomized prospective study was performed to compare the success rate for tracheal intubation over an 11-F PAEC between patients in the sniffing position and those with cervical spine immobilization created using a manual in-line axial stabilization (MIAS) technique. ${ }^{9}$ In addition, we investigated the effects of external laryngeal pressure on the passage of an endotracheal tube in such situations.

\section{Methods}

This study was approved by the Hospital Ethics Committee. We received written informed consent from all patients. Patients $(n=100$; ASA physical status I-II, 18-60 yr) undergoing elective surgery that required general anesthesia and tracheal intubation were enrolled. Exclusion criteria included a known difficult airway, cervical spine or airway disease, cardiorespiratory or cerebrovascular disease, body mass index $>35 \mathrm{~kg} \cdot \mathrm{m}^{-2}$, or a risk factor for regurgitation.

The patients were prospectively randomized with a computer-generated random allocation to one of two groups: Group S and Group M. Allocation concealment was achieved with the use of sealed opaque envelopes to mask the randomization sequence. In Group $S$, the sniffing position ${ }^{10}$ was maintained throughout the study period; in Group M, a MIAS of the head and neck was applied to patients to simulate the clinical scenario in which the technique would be used in cases of cervical spine injury. The pillow was removed immediately before PAEC-guided intubation, and an experienced assistant nurse immobilized the patient's neck by using the MIAS technique, i.e., holding the sides of the neck and the mastoid processes, preventing movement of the head and neck. This position was maintained during tracheal intubation.

Four members of the anesthesia team were present for each procedure. They were designated as: a) the laryngoscopist who evaluated glottic exposure according to the Cormack and Lehane (C-L) scale ${ }^{11}$ and then initially inserted the PAEC into the trachea; $b$ ) the intubator who railroaded the tube over the PAEC into the trachea; c) the first assistant nurse; and d) the second assistant nurse. The role of the first assistant nurse was to maintain the two different head and neck positions during simulated reintubation. The role of the second assistant nurse was to perform an external laryngeal pressure maneuver and record the intubation time (defined as the time from insertion of the tube into the PAEC to confirmation of tracheal intubation by capnography). The second assistant nurse had previously been trained to apply about $0.5-\mathrm{cm}$ backward gentle pressure on the thyroid cartilage during the third attempt.

An 11-F PAEC (Cook Critical Care, Bloomington, IN, USA) was used in all patients. The semi-rigid PAEC (yellow-coloured) made of radiopaque polyurethane was $83 \mathrm{~cm}$ in length, had an outer diameter (OD) of $4 \mathrm{~mm}$ and an inner diameter (ID) of $2.3 \mathrm{~mm}$, and a hollow lumen. A 7.5-mm ID wire-reinforced tube (Mallinkrodt Medical, Athlone, Ireland) was used in all cases.

Patients were premedicated with $5 \mathrm{mg}$ of dexamethasone administered intravenously. The patient was placed in the supine position with the head on a $6-\mathrm{cm}$ firm pad with a gel ring. Standard monitors were used, and anesthesia was induced with lidocaine $30 \mathrm{mg}$, propofol $1.5-2.0 \mathrm{mg} \cdot \mathrm{kg}^{-1}$, vecuronium 0.1 $\mathrm{mg} \cdot \mathrm{kg}^{-1}$, and fentanyl $\mathrm{l} \mu \mathrm{g} \cdot \mathrm{kg}^{-1} i v$. The lungs were ventilated with a facemask until the loss of the fourth 
twitch in the train-of-four in response to ulnar nerve stimulation. During this period, the lungs were ventilated with $100 \%$ oxygen and sevoflurane $1-2 \%$. Thereafter, under direct laryngoscopic view, glottic exposure was rapidly graded according to the C-L scale. In each case, if the glottic view was grade 3 or 4 , conventional laryngoscopic intubation was performed promptly, and the patient was then excluded from the study. If the glottic view was grade 1 or 2 , the following sequence of consecutive maneuvers was employed in all patients. Under direct laryngoscopic view, the first anesthesiologist carefully inserted the PAEC into the trachea, placing it at a depth of $5 \mathrm{~cm}$ below the vocal cord to avoid carinal irritation or accidental dislodgement. Immediately after removal of the laryngoscope, the other experienced anesthesiologist (> 50 PAEC-guided tracheal tube exchanges) gently railroaded the tracheal tube over the PAEC and into the trachea. The tube was then advanced over the PAEC with the preformed concavity oriented anteriorly with its bevel facing to the left. If the first insertion trial failed, the tube was withdrawn slightly and then gently rotated counterclockwise by $90^{\circ}$ while simultaneously attempting to reinsert it. If the second insertion trial also failed, one additional attempt was made using external laryngeal pressure before changing to conventional laryngoscopic intubation. If the total duration of all procedures was over $90 \mathrm{sec}$, or if $\mathrm{SPO}_{2}$ was reduced to $<93 \%$, the administration of $100 \%$ oxygen was provided by bag-mask ventilation with the PAEC lateralized to the corner of the mouth to optimize the mask seal. Thereafter, these patients were intubated with the aid of a laryngoscope and were excluded from the study.

The primary outcome was the overall success rate of passing the tube over the PAEC and into the trachea within three attempts. For the purpose of sample size calculation, we estimated an $80 \%$ incidence of successful passing of the tube into the trachea in the sniffing position, based on a previously reported rate of $86 \%^{12}$ using a fibrescope with a slightly larger OD $(4.2 \mathrm{~mm})$ than that of the PAEC used here. From our preliminary observations, we adopted the one-tailed alternative hypothesis that the overall success rate in Group M would be lower than that in Group S. We then considered that the overall success rate would be at least $55 \%$ for incorporating the use of the PAEC into pre-formulated extubation strategies in patients requiring cervical spine immobilization. We calculated that 42 patients per group would be required to provide $80 \%$ power for detecting an absolute difference of $25 \%$ between groups. To compensate for
TABLE I Patient characteristics

\begin{tabular}{lcl}
\hline & $\begin{array}{c}\text { Group } M \\
(n=46)\end{array}$ & $\begin{array}{c}\text { Group } S \\
(n=47)\end{array}$ \\
\hline Gender $(\mathrm{M} / \mathrm{F})$ & $19 / 27$ & $26 / 21$ \\
Age $(\mathrm{yr})$ & $48.1 \pm 15.2$ & $48.7 \pm 18.6$ \\
ASA $(\mathrm{I} / \mathrm{II})$ & $25 / 21$ & $33 / 14$ \\
Weight $(\mathrm{kg})$ & $61.7 \pm 9.6$ & $64.7 \pm 10.1$ \\
Height $(\mathrm{cm})$ & $162.3 \pm 8.7$ & $163.9 \pm 8.5$ \\
BMI $\left(\mathrm{kg} \cdot \mathrm{m}^{-2}\right)$ & $23.4 \pm 2.6$ & $24.0 \pm 2.4$ \\
Cormack-Lehane grade $(\mathrm{I} / \mathrm{II})$ & $37 / 9$ & $36 / 11$ \\
\hline
\end{tabular}

Values are expressed as means \pm standard deviation or number of patients. Group $\mathrm{M}=$ cervical spine immobilization using a manual-in-line stabilization technique; Group $S$ = sniffing position; $\mathrm{BMI}=$ body mass index .

possible dropouts, we thus enrolled 50 patients per group.

The data were analyzed using SPSS 12 (SPSS. Inc., Chicago, IL, USA). Continuous data were analyzed using the unpaired two-tailed $t$ test or the MannWhitney $U$ test, where applicable. Categorical data were analyzed using Pearson's $\chi^{2}$-test with continuity correction or Fisher's exact test, where applicable. The $z$-test was used to compare the proportions of successful advancement of the tube at each attempt between the groups, and the logrank test was used to compare intubation times. Differences were considered statistically significant at $P<0.05$.

\section{Results}

Two patients were screened out of the study by our exclusion criteria, and 100 patients (between November 2007 and February 2008) were subsequently allocated to two equally-sized groups. At the initial laryngoscopic inspection, three patients in Group M and two patients in Group $S$ were excluded because of a C-L grade $\geq 3$. Thus, 93 patients ( 46 in Group M, 47 in Group S) were included in the final analysis. There was no difference in demographic or airway assessment characteristics between the groups (Table I). No adverse event was documented in either group.

Both groups were comparable with respect to the success rate on the first attempt (Table II). In the 16 patients in Group M and the 32 patients in Group S, in whom tracheal intubation was unsuccessful on the first attempt, the tube passed smoothly into the trachea on the second attempt following a $90^{\circ}$ counterclockwise rotation and re-advancement (cumulative success rate after the second attempt: $41.3 \%$ vs $72.3 \%$, respectively; $P=0.003$, Table II). In an additional five patients in Group $M$ and an additional two patients in Group S, successful passing of the tube was accomplished after the application of external laryngeal pressure. Thus, 
TABLE II Results of passing the tracheal tube over an 11-F Cook pediatric airway exchange catheter and into the trachea

\begin{tabular}{lccc}
\hline & $\begin{array}{l}\text { Group } M \\
(n=46)\end{array}$ & $\begin{array}{l}\text { Group } S \\
(n=47)\end{array}$ & P-value \\
\hline $\begin{array}{l}\text { Successful after the } \\
\text { first attempt; } n(\%)\end{array}$ & $3(6.5)$ & $2(4.3)$ & 0.677 \\
$\begin{array}{l}\text { Successful after initial } \\
\text { two attempts; } n(\%)\end{array}$ & $19(41.3)$ & $34(72.3)$ & $0.003^{*}$ \\
$\begin{array}{l}\text { Overall successful after } \\
\text { three attempts; } n(\%)\end{array}$ & $24(52.2)$ & $36(76.6)$ & $0.018^{*}$ \\
$\begin{array}{l}\text { Unsuccessful after three } \\
\text { attempts; } n(\%)\end{array}$ & $22(47.8)$ & $11(23.4)$ & $0.02^{*}$ \\
\begin{tabular}{l} 
Intubation time (sec) \\
\hline
\end{tabular} & $41.9 \pm 8.6$ & $32.2 \pm 7.6$ & $<0.001^{*}$ \\
\hline
\end{tabular}

Values are expressed as means \pm standard deviation or number and percentage of patients. Group $M=$ cervical spine immobilization using a manual-in-line stabilization technique; Group $S$ = sniffing position. "Statistically significant difference $(P<0.05)$.

the overall success rate, after three attempts in Group $\mathrm{M}$, was significantly lower than that in Group S (52.2\% vs $76.6 \%$, respectively; $P=0.018$, Table II). For the patients in whom the tube was passed successfully into the trachea, the mean intubation time in Group $M$ was significantly longer than that in Group S $(41.9 \pm$ 8.6 vs $32.2 \pm 7.6 \mathrm{sec}$, respectively; $P<0.001$; Table II). To assess the temporal component of the success of intubation, Kaplan-Meier plots were constructed (Figure).

\section{Discussion}

The main finding of this study was that 11-F PAECguided tracheal "trial" reintubation failed in almost half of the patients with simulated cervical spine immobilization, even with $90^{\circ}$ counterclockwise rotation of the tube and external laryngeal manipulation. In contrast, the success rate was significantly improved to $76.6 \%$ in patients in the sniffing position.

Despite several suggested extubation criteria, ${ }^{13-15}$ it is difficult to reliably predict which patients will develop respiratory distress following extubation. Generally, tracheal reintubation rates of 6-19\% have been reported in surgical ICU patients. ${ }^{14,15}$ Considering the increased risk of failure in reintubating patients with cervical spine immobility or instability, extubation in these patients can be a major challenge, even for experienced anesthesiologists.

Several previous studies ${ }^{6-8,16}$ have suggested the use of a pediatric-sized (11-F or 14-F) airway exchange catheter as an option for performing a safe trial of a potentially difficult extubation. Dosemeci et al. ${ }^{7}$ even suggested that, because this technique could obviate unnecessary tracheostomy in patients at risk for difficult reintubation, it should be used routinely after major neck surgery. However, as mentioned by

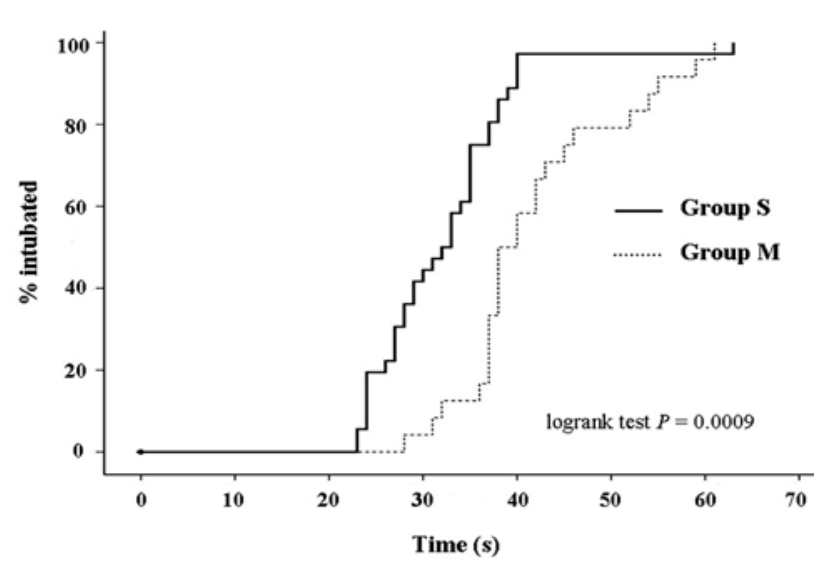

FIGURE Kaplan-Meier plot demonstrating the success of simulated reintubation using an 11-F Cook pediatric airway exchange catheter as a function of time.

Benumof, ${ }^{17}$ the most important consideration for this apparently attractive concept is the success rate of actually passing a tracheal tube over the PAEC and into the trachea during reintubation. When considering the possibly life-threatening sequelae in failed cases, a clinically acceptable success rate must be assured for this technique before advocating its use as a reliable airway management option. Although Mort ${ }^{16}$ reported an $87 \%$ first-pass success rate $(92 \%$ overall success by reducing the size of the tracheal tube) in an observational study of a relatively large cohort of difficult airway patients, we doubted whether this apparently favourable result would be achievable in patients with cervical spine immobilization. Thus, a strict MIAS technique during the mimic reintubation was used in Group M to simulate PAEC-guided reintubation in patients with known or suspected cervical spine injury.

When attempting to insert the tube with the preformed concavity oriented anteriorly (with the bevel facing to the left) during fibreoptic intubation, the bevelled tip can impinge on the right arytenoid cartilage or the inter-arytenoid soft tissues and impede advancement through the glottis. ${ }^{18,19}$ This has also been described with the passage of the tube over a gum-elastic bougie. ${ }^{20}$ The main cause of this constriction is the creation of a cleft along the tube bevel by the difference in the OD of the fibrescope or bougie and the ID of the tube. In this study, we used a PAEC with an OD of $4 \mathrm{~mm}$ and a tracheal tube with ID of $7.5 \mathrm{~mm}$. We believe that this disparity in diameters contributed to our higher first-path intubation failure rates in both groups. As shown in the study of Mort, ${ }^{16}$ reducing the size of the tube may be a viable solution. 
That is to say, a stepwise reintubation trial may be a possible solution to increase the success rate of PAECguided intubation in both groups. A small-sized tracheal tube $(6.0$ or $6.5 \mathrm{~mm}$ ID) could be attempted initially, and, if it fails, a larger tube could then be attempted. A reverse sequence trial may also be possible. Although such experiments would be cumbersome in actual clinical situations, they would provide valuable information. Using a larger PAEC [e.g., 14-F $(4.7 \mathrm{~mm} \mathrm{OD})$ or $19-\mathrm{F}(6.3 \mathrm{~mm} \mathrm{OD})]$ is also possible, but it eventually increases a patient's intolerance. ${ }^{8,16}$ Moreover, it may increase the potential risks of retention of tracheal secretions due to impaired coughing and aspiration caused by incomplete glottic closure when the PAEC is in the indwelling state. ${ }^{8}$

The size of the tracheal tube or its tip design may also influence the passing ability of the tube. ${ }^{18,19} \mathrm{We}$ used the same size of wire-reinforced tube $(7.5 \mathrm{~mm}$ ID) in both male and female patients. As a wire-reinforced tube has greater side-to-side flexibility and a more obtuse angle at the distal end than a conventional polyvinylchloride tube, it is less likely to impinge on pharyngo-laryngeal structures during fibreoptic intubation. ${ }^{19}$

Another possible determining factor may be the rigidity of the PAEC. As an airway exchange catheter becomes stiffer, its usefulness as a stylet for intubation increases, but the patient's discomfort with the indwelling catheter and the risk of airway damage during insertion also increase. In fact, one case of tracheal laceration has been reported after using a more rigid 11-F PAEC (the small, green one produced by Cook Critical Care Products). ${ }^{21}$

Counter clockwise rotation of the tube through $90^{\circ}$ has been suggested to overcome difficulties with tube insertion during fibreoptic intubation. ${ }^{18,19}$ This maneuver will realign the bevel of the tube from the vertical to the horizontal plane, making it less likely to encounter any laryngeal structures. Thus, it was incorporated as a rescue maneuver during the second attempt in this study, and it resulted in a significant improvement for successful railroading in both groups (from 6.5 to $41.3 \%$ in Group M vs from 4.3 to $72.3 \%$ in Group S). The main reason for the difference in the improvements of second path intubation success rates between the two groups may be the different angles of railroading paths of the tube between the groups. Clearly, during railroading over the PAEC, the main determinant of success is the alignment of the pharyngeal axis with the laryngeal axis. Thus, the angle between these two axes must be minimized. However, in Group M, the MIAS technique limited the head extension and neck flexion, which are necessary for optimal alignment between these two axes, and, in so doing, it prevented centralization of the tube in front of the glottis.

In this study, the application of external laryngeal pressure provided appreciable improvement for successful railroading of the tube in both groups (absolute increase: $10.9 \%$ in Group M vs $4.3 \%$ in Group S). Although direct visualization was not performed in the present study, external laryngeal manipulation may move the glottis posteriorly, thereby making the railroading path of the tube approach a straighter line than is achievable without it. Thus, it provides greater passing ability of the tube through the glottis in both groups. As the pre-existing pharyngo-laryngeal angle in Group $M$ was larger than that in Group S, the beneficial effect on the passing ability of the tube seems to be much greater in Group M than in Group S. For the patients who had the tube successfully passed into the trachea, the mean time in Group $S$ was significantly shorter than that in Group M. However, the difference in the times (about ten seconds) was so short that it was probably not clinically relevant.

The main limitation of this study is that it was not performed in a blinded manner in actual difficult airway patients with cervical instability or immobility. It would be unethical to recruit such patients, because no data are currently available regarding the safety of PAEC-guided reintubation in patients with cervical spine immobilization. The anesthesiologist who intubated the patients was not blind to the head and neck position, and this may be a potential source of bias. However, it is technically impossible for the intubator to be unaware of the position during the study procedure. Another limitation is that this study was performed under scheduled anesthesia conditions, including the use of a muscle relaxant. The actual reintubation success rate for awake or agitated patients may be lower than that recorded in this study. Successful passage of the tube over the PAEC and into the trachea can be significantly impeded by resistive tongue movements, coughing, or bucking at insertion. Although we attempted to gently rotate and railroad the tube over the PAEC, forceful attempts to pass the tube through the glottis may be more successful in some patients. Nevertheless, this can lead to damage to the vocal cord or to bleeding or swelling of the upper airway, which may then render other airway management options impossible. A further limitation is that gentle laryngoscopy to retract the tongue was not used in the present study. Although its beneficial effects have never been quantified, it seems to be conceptually useful and has been recommended to facilitate passage of a tracheal 
tube over a PAEC..$^{22}$ Unfortunately, this potentially beneficial maneuver is variably limited or impossible in patients with cervical immobility or instability, according to the cervical collar used or the severity of cervical instability, and we excluded it in this study. Furthermore, its standardization (e.g., how much is "gentle"?) could be an additional source of observational bias. However, since it seems to have potential benefit, there is no reason not to use laryngoscopy, if possible, in clinical situations. Finally, even though the outer surface of the tube tip was not lubricated in the present study, it seems to be conceptually appropriate, but further study is necessary to demonstrate whether it increases the success rate of PAEC-guided reintubation.

In conclusion, we strongly recommend that an 11-F Cook airway exchange catheter not be used for maintaining continuous access to the airway after extubation in patients with cervical immobility or instability. Unless and until further studies demonstrate a favourable risk/benefit ratio of this technique, possibly using a different size or design of airway exchange catheter, the application of this practice to patients requiring cervical spine immobilization should be reserved.

\section{References}

1 Demling RH, Read T, Lind LJ, Flanagan HL. Incidence and morbidity of extubation failure in surgical intensive care patients. Crit Care Med 1988; 16: 573-7.

2 Crosby E. Airway management after upper cervical spine injury: what have we learned? Can J Anesth 2002; 49: 733-44.

3 Hastings RH, Kelley SD. Neurologic deterioration associated with airway management in a cervical spineinjured patient. Anesthesiology 1993; 78: 580-3.

4 Listello D, Sessler CN. Unplanned extubation. Clinical predictors for reintubation. Chest 1994; 105: 1496-503.

5 Meister $S$. Emerging risks: inappropriately prolonged mechanical ventilation. QRC Advis 1993; 9: 1-3.

6 Loudermilk EP, Hartmannsgruber M, Stoltzfus DP, Langevin $P B$. A prospective study of the safety of tracheal extubation using a pediatric airway exchange catheter for patients with a known difficult airway. Chest 1997; 111: 1660-5.

7 Dosemeci L, Yilmaz $M$, Yegin A, Cengiz $M$, Ramazanoglu $A$. The routine use of pediatric airway exchange catheter after extubation of adult patients who have undergone maxillofacial or major neck surgery: a clinical observation study. Crit Care 2004; 8: R385-90.

8 Biro P, Preibe HJ. Staged extubation strategy: is an airway exchange catheter the answer? Anesth Analg 2007; 105: 1182-5.

9 Kihara S, Yaguchi $\Upsilon$, Taguchi N, Brimacombe JR, Watanabe $S$. The StyletScope is a better intubation tool than a conventional stylet during simulated cervical spine immobilization. Can J Anesth 2005; 52: 105-10.

10 Gal TJ. Airway management. In: Miller RD (Ed.). Anesthesia, 6th ed. Philadelphia: Elsevier Churchill Livingstone Inc.; 2005: 1617-52.

11 Cormack RS, Lehane J. Difficult tracheal intubation in obstetrics. Anaesthesia 1984; 39: 1105-11.

12 Jackson AH, Wong P, Orr B. Randomized, controlled trial of the double setup tracheal tube during fibreoptic orotracheal intubation under general anaesthesia. Br J Anaesth 2004; 92: 536-40.

13 Miller KA, Harkin CP, Bailey PL. Postoperative tracheal extubation. Anesth Analg 1995; 80: 149-72.

14 Tabvanainen J, Salmenpera M, Nikki P. Extubation criteria after weaning from intermittent mandatory ventilation and continuous positive airway pressure. Crit Care Med 1983; 11: 702-7.

15 DeHaven CB Jr, Hurst JM, Branson RD. Evaluation of two different extubation criteria: attributes contributing to success. Crit Care Med 1986; 14: 92-4.

16 Mort TC. Continuous airway access for the difficult extubation: the efficacy of the airway exchange catheter. Anesth Analg 2007; 105: 1357-62.

17 Benumof JL. Airway exchange catheters: simple concept, potentially great danger. Anesthesiology 1999; 91: 342-4.

18 Johnson DM, From AM, Smith RB, From RP, Maktabi $M A$. Endoscopic study of mechanisms of failure of endotracheal tube advancement into the trachea during awake fiberoptic orotracheal intubation. Anesthesiology 2005; 102: 910-4.

19 Brull SJ, Wiklund R, Ferris C, Connelly NR, Ehrenwerth $J$, Silverman DG. Facilitation of fiberoptic orotracheal intubation with a flexible tracheal tube. Anesth Analg 1994; 78: 746-8.

20 Dogra S. Falconer R, Latto IP. Successful difficult intubation. Tracheal tube placement over a gum-elastic bougie. Anaesthesia 1990; 45: 774-6.

21 Thomas V, Neustein SM. Tracheal laceration after the use of an airway exchange catheter for double-lumen tube placement. J Cardiothorac Vasc Anesth 2007; 21: 718-9.

22 Benumof JL. Airway exchange catheters for safe extubation: the clinical and scientific details that make the concept work. Chest 1997; 111: 1483-6. 